\title{
Sclerotherapy in the treatment of a recurrent lymphocele
}

\author{
A. J. POPE \\ M.B., B.S
}

M. C. ORMISTON

F.R.C.S.

\author{
D. G. BOGOD \\ M.B., B.S. \\ Department of Urology, The Middlesex Hospital, Mortimer Street, London W1A INP
}

\section{Summary}

The management of postoperative lymphoceles is often lengthy and unsatisfactory. We describe the successful treatment of a recurrent lymphocele by the repeated injection of sodium tetradecylsulphate (STD) after percutaneous aspiration. This method of treatment has not to our knowledge been previously described.

\section{Case report}

A 71-year-old male underwent a diagnostic excision biopsy of a palpable right external inguinal lymph node in April 1980. Subsequently he was found to have disseminated carcinoma of the prostate with extensive involvement of the internal iliac lymph nodes.

Over the next 6 weeks he developed a large lymphocele at the site of the lymph node excision, measuring 11 by $8 \mathrm{~cm}$ (Fig. 1). Despite surgical excision of this lymphocele, ligation of all visible lymphatic channels and prolonged postoperative suction drainage, it re-formed. Subsequently, repeated needle aspirations for 8 days yielded more than $100 \mathrm{ml}$ of lymph per day with no sign of any reduction in the volumes aspirated.

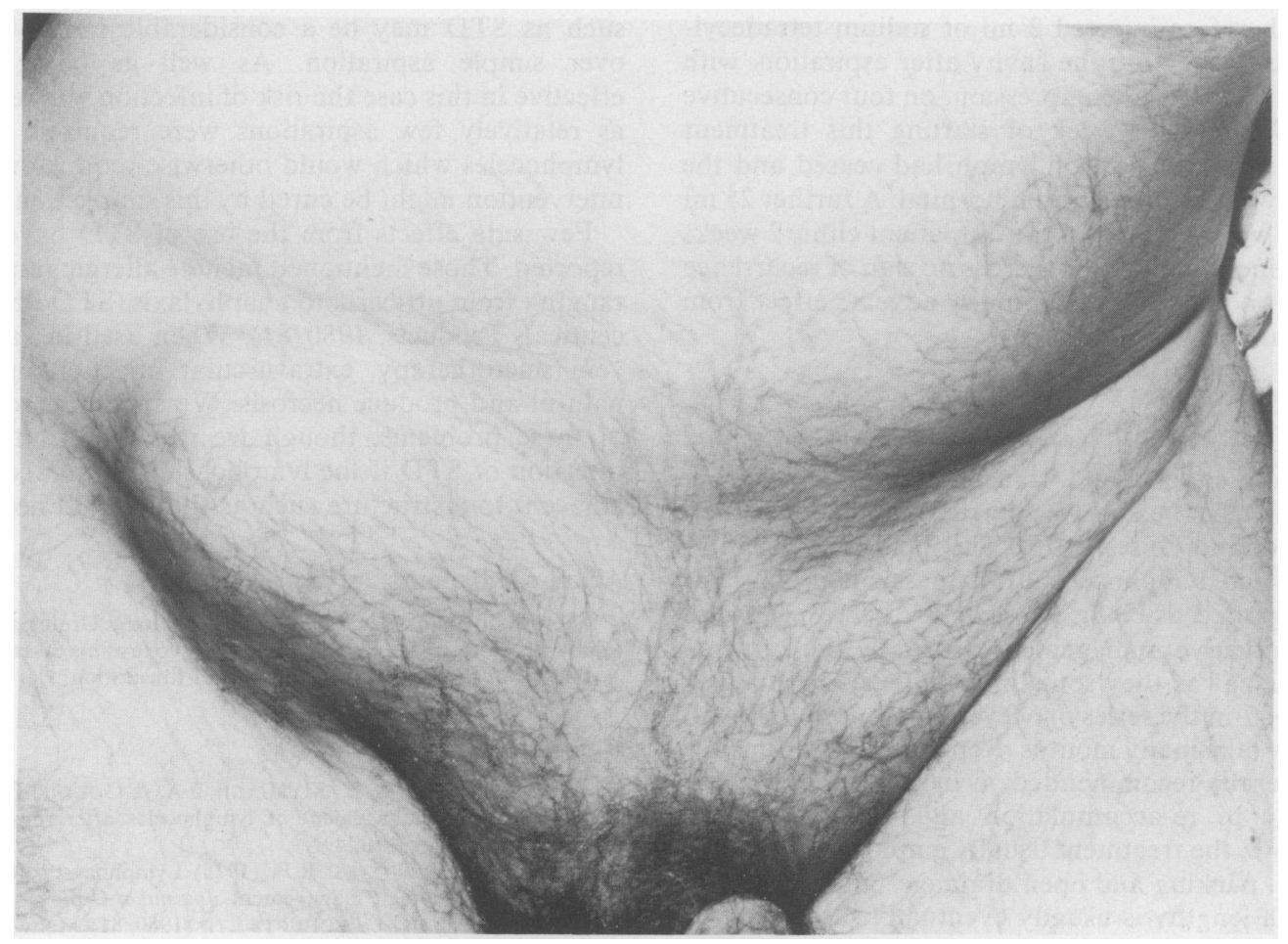

FiG. 1. Right inguinal lymphocele before treatment. 


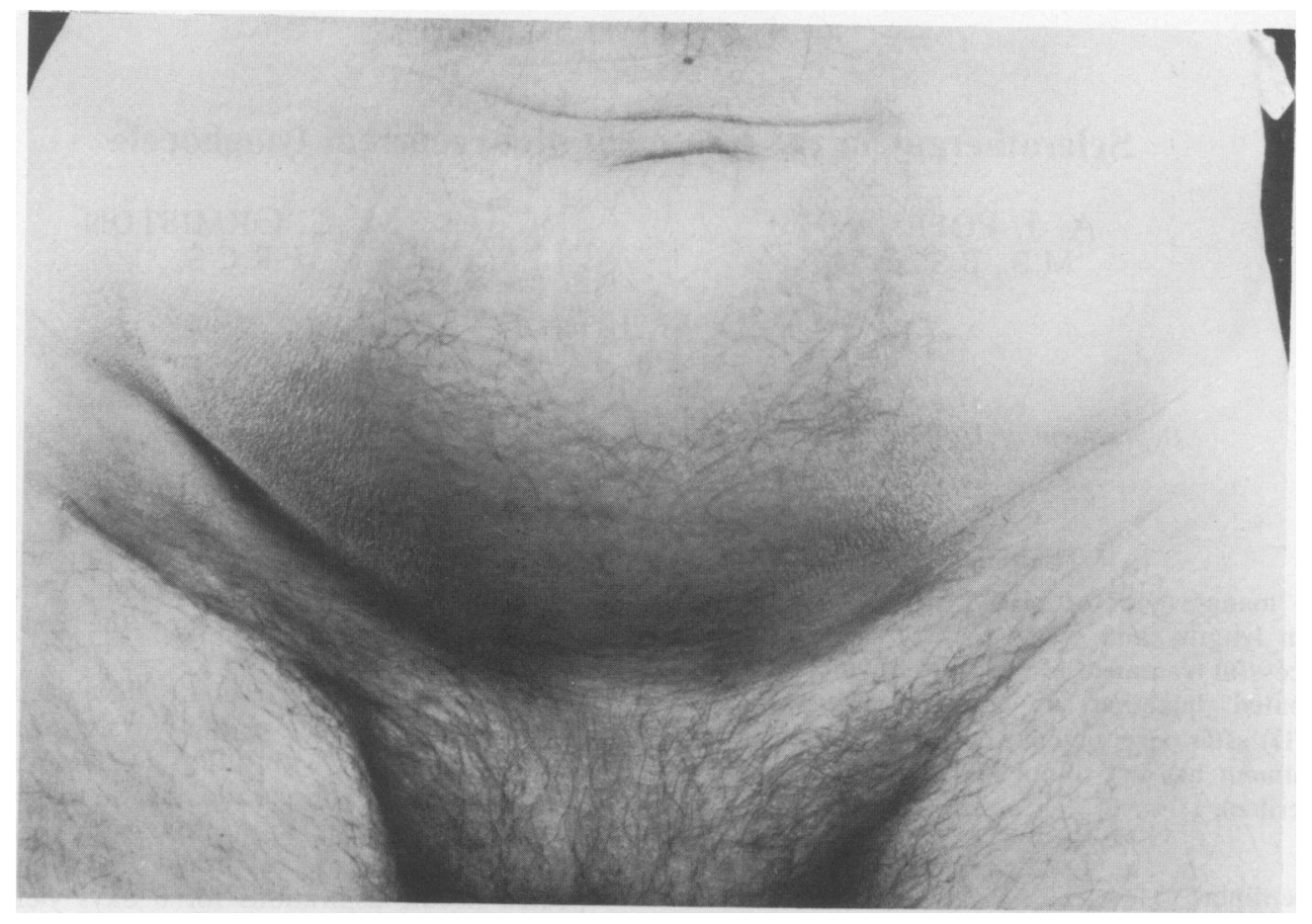

FIG. 2. Lymphocele nine months after sclerotherapy.

We therefore injected $2 \mathrm{ml}$ of sodium tetradecylsulphate (STD) into the cavity after aspiration, with immediate external compression, on four consecutive days. Within one week of starting this treatment further accumulation of lymph had ceased and the patient was discharged from hospital. A further $25 \mathrm{ml}$ of fluid was aspirated in the outpatient clinic 2 weeks later. Nine months later there is no sign of recurrence (Fig. 2), nor has there been any adverse effect from this treatment.

\section{Discussion}

Most lymphoceles have been reported in conjunction with either renal transplantation (Meyers et al., 1977), or extensive pelvic lymphadenectomy (Basinger and Gittes, 1975). The incidence of significantly-sized lymphoceles after these operations has been reported as being $3 \%$ and $13-50 \%$ respectively.

Conservative management is usually the first line of treatment as they sometimes settle spontaneously ( 2 out of 7 in the series of Meyers et al., 1977), though this may take many months. Repeated aspirations are not generally recommended, as in most series this has led only to re-accumulation and often to sepsis. Therefore, the treatment usually employed is surgical incision, packing and open drainage. This procedure although lengthy is usually eventually successful.

We would suggest that the use of sclerosing agents such as STD may be a considerable improvement over simple aspiration. As well as being most effective in this case the risk of infection was reduced as relatively few aspirations were required. Many lymphoceles which would otherwise require surgical intervention might be cured by this simple treatment.

Few side effects from the use of STD have been reported. Those mentioned include allergic responses ranging from urticaria to anaphylaxis (STD Pharmaceuticals Products, 1980/81). When used in varicose vein sclerotherapy, extravascular injection may be painful and produce necrosis. We encountered none of these problems, though we would not advocate injection of STD if the lymphocele was immediately adjacent to a structure such as the femoral nerve.

\section{Acknowledgments}

We wish to thank Mr E. Milroy, Consultant Urologist at the Middlesex Hospital for permission to report one of his cases, and $\mathrm{Mr}$ A. Phillips of the Department of Medical Illustration.

\section{References}

Meyers, A.M., Levine, E., MYburgh, J.A. \& Goudie, E. (1977) Diagnosis and management of lymphoceles after renal trans plantation. Urology, 10, 497.

BASINGER, G.T. \& GITTES, R.F. (1975) Lymphocyst: ultrasound diagnosis and urologic management. Journal of Urology, 114, 740. STD Pharmaceutical Products LTD (1980/81) Manufacturers information. Data Sheet Compendium, 1058. 